\begin{tabular}{|c|c|c|}
\hline ITC 2/46 & \multicolumn{2}{|c|}{$\begin{array}{c}\text { An Adaptive Neural Network Control Scheme for Stabilizing } \\
\text { Chaos to the Stable Fixed Point }\end{array}$} \\
\hline $\begin{array}{l}\text { Vol. } 46 / \text { No. } 2 / 2017 \\
\text { pp. } 219-227\end{array}$ & Received 2016/01/12 & Accepted after revision 2017/04/18 \\
\hline $\begin{array}{l}\text { Do1 10.5755/j01.itc.46.2.13962 } \\
\odot \text { Caunas University of Technology }\end{array}$ & \multicolumn{2}{|c|}{ Crossef http://dx.doi.org/10.5755/j01.itc.46.2.13962 } \\
\hline
\end{tabular}

\title{
An Adaptive Neural Network Control Scheme for Stabilizing Chaos to the Stable Fixed Point
}

\section{Kursad Gokce}

Tübitak Marmara Research Center, Energy Institute, Automotive Center of Excellence, 41470, Izmit, Turkey, e-mail: kursad1258@gmail.com

\section{Yilmaz Uyaroglu}

Sakarya University, Engineering Faculty, Department of Electrical \& Electronics Engineering, 54187, Sakarya,

Turkey, e-mail: uyaroglu@sakarya.edu.tr

Corresponding author: kursad1258@gmail.com

A neural network control scheme with a novel adaptive learning rate is proposed to stabilize the chaotic trajectory of the chaotic system to a stable fixed point. A new approach is proposed to determine the stability of the fixed points in which the eigenvalues of the Jacobian matrix of the chaotic system at different values of the chaoticity parameter are evaluated and a look-up table is created to find a suitable fixed point that has a negative Lyapunov exponent. During learning phase of the neural network, weight parameters are adjusted so that the chaotic trajectory converges to a stable fixed point and the maximum Lyapunov exponent of the controlled system becomes negative. The effectiveness of the proposed method is investigated through simulation studies on 2 dimensional Ikeda map, which is produced by a semiconductor laser system.

KEYWORDS: chaos control, adaptive control, neural network, stabilitiy, bifurcation.

\section{Introduction}

Today, the electronic systems built up from microelectronic circuits can exhibit chaotic behavior under some circumstances. For example, a digital filter can produce chaos under a certain condition, and this may be useful in crypto systems [27]; or some chaotic systems can be used for secure communication applications [4]. However, if chaos is not controlled, it may result in system failure and malfunction.

Thus, controlling chaos via different control schemes has received great interest in recent years after it 
was first introduced by Ott et al. [25]. In OGY-like methods $[28,17,5,7]$, a small perturbation is applied to some parameter of the system to keep the chaotic trajectory in the vicinity of the target periodic orbit, when the chaotic trajectory enters a small neighborhood of the corresponding fixed point. However, it is not always an easy task to find a suitable control parameter in the system and a priori knowledge of the unstable periodic orbits is required to apply the control algorithm. Furthermore, these methods are highly sensitive to noise [12].

Linear controllers have also been used for chaos control. A piecewise linear feedback control [6] or a state feedback control [13] have been realized to stabilize the chaotic Chua's circuit. These types of controllers have a simple structure and can be easily applied in engineering problems; however, they are able to control the system for specific operating conditions.

The control problem of chaotic systems with uncertainty and disturbance has been studied by researchers using different robust control techniques. In [1], a sliding mode controller has been designed to stabilize the unstable periodic orbits of two-dimensional Hénon map with external disturbances. Sliding mode controllers have also been used to regulate and synchronize the chaotic systems to their equilibrium state $[15,29,16]$. In [20], a fuzzy model based design has been developed for trajectory tracking control of chaotic systems. However, fuzzy models are generally intuitive and require well-tuned control parameters.

Backstepping is one of the most promising Lyapunov based adaptive robust control techniques, which has been used for stabilization and tracking control of continuous time [31,23,24] and discrete time [21] chaotic systems as well as of nonlinear chaotic systems with bounded uncertainties and external disturbances [2, 22]. Adaptive backstepping controllers have a good performance for stabilizing the uncertain dynamical systems but ignore the parameter estimation errors in updating rules. To overcome these drawbacks, a flexible modular design has been proposed in [30] so that the parameter identifier and the controller modules have been independently designed.

Recently, neural network (NN) based control algorithms have attracted great interest in control and synchronization of chaotic systems because of their ability to deal with uncertainty and noise. In [19], a
NN based algorithm has been utilized to stabilize the chaotic motion in chaotic Hénon map to a desired target trajectory. In [32], the chaotic motions of the Hénon and Logistic maps have been converted to a regular periodic motion by using a back propagation NN algorithm. In [10], a similar algorithm has been developed to control the chaotic trajectory of the Ikeda system to the equilibrium point.

In the stability analysis of chaotic systems, the Lyapunov exponent is an important quantitative indicator of chaotic dynamics, which is used to measure the convergence or divergence of nearby trajectories [9]. In [11], universal learning networks have been used to generate and eliminate the chaotic phenomena by controlling the maximum Lyapunov exponent of the system. In [26], a time delayed feedback controller has been proposed to stabilize the unstable periodic orbits of chaotic system, where the maximum Lyapunov exponent becomes negative.

In this paper, a back propagation NN algorithm with a novel adaptive learning rate [8] has been proposed to stabilize the chaotic trajectory of the discrete chaotic Ikeda system to the stable fixed point. First, the chaotic behavior of the Ikeda system depending on the choice of the chaoticity parameter has been investigated through bifurcation and the Lyapunov exponent analysis. Then, stability of the fixed points has been examined and a stability region for the stable fixed points with negative Lyapunov exponents has been defined. Based on the stability region, a lookup table has been built to determine the target stable fixed point for a chosen chaoticity parameter. With the improved NN scheme, weight parameters are adjusted so that the chaotic trajectory of the controlled system converges to a target stable fixed point, where the maximum Lyapunov exponent is negative. Time series plots and the maximum Lyapunov exponent calculations show that the proposed control scheme has been successfully applied to the chaotic system for controlling the chaotic trajectory.

\section{Discrete time chaotic system}

In this paper, Ikeda map, which represents the dynamics of a laser pulse in an optical cavity, is studied as a two-dimensional chaotic system. The map equation is given in [14] as: 


$$
\begin{aligned}
& x(k+1)=F(x, y)=p+B(x(k) \cos (t)-y \sin (t)), \\
& y(k+1)=G(x, y)=B(x(k) \cos (t)+y \sin (t)), \\
& t=k-\alpha /\left(1+x_{k}^{2}+y_{k}^{2}\right) .
\end{aligned}
$$

Eq. (1) exhibits a strange attractor with parameters $p=1, \alpha=6, k=0.4$ and $B=0.9$ as shown in Fig. 1 [3].

\section{Figure 1}

The attractor of Ikeda map

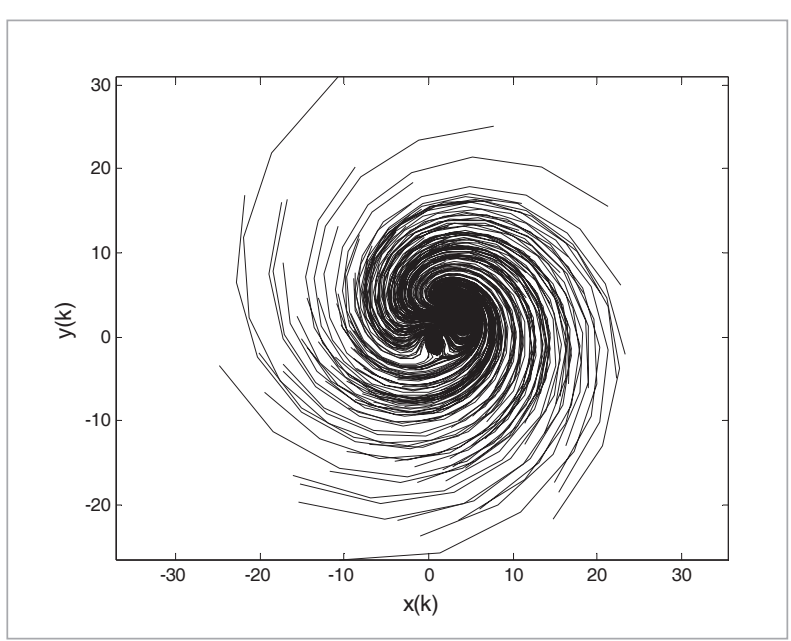

For a $2 \mathrm{D} \operatorname{map}_{*},\left(x_{*}^{*}, y_{*}^{*}\right)$ is a fixed point if it satisfies $F\left(x^{*}, y^{*}\right)=x^{*}, G\left(x^{*}, y^{*}\right)=y^{*}$. Let $\left(x^{*}, y^{*}\right)$ be the fixed point, then, using Taylor expansions, one can obtain the Jacobian matrix as:

$$
J(x, y)=\left[\begin{array}{ll}
\frac{\partial F}{\partial x} & \frac{\partial F}{\partial y} \\
\frac{\partial G}{\partial x} & \frac{\partial G}{\partial y}
\end{array}\right]_{x=x^{*}, y=y^{*}}
$$

To understand the stability of a fixed point, one can check the eigenvalues of the Jacobian matrix given by Eq. (2). If the magnitude of each eigenvalue is smaller than one, then the fixed point is attracting a stable point. If the magnitude of each eigenvalue is bigger than one, then the fixed point is repelling an unstable point. If at least one eigenvalue is smaller than one and at least one eigenvalue is bigger than one, then the fixed point is unstable saddle point.

In order to evaluate the chaotic behavior of a dyna- mical system, Lyapunov exponents are used to identify the separation or attraction of initially nearby trajectories. Let $M$ be the matrix given by the product of Jacobians as:

$$
M=\prod_{i=1}^{N} J\left(x_{i}, y_{i}\right)
$$

Then, Lyapunov exponents of two-dimensional map, $\sigma_{1}$ and $\sigma_{2}$, are calculated by:

$$
\begin{aligned}
& \sigma_{1}=\lim _{N \rightarrow \infty} \frac{1}{N} \operatorname{In}\left|\lambda_{1}\right|, \\
& \sigma_{2}=\lim _{N \rightarrow \infty} \frac{1}{N} \operatorname{In}\left|\lambda_{2}\right|,
\end{aligned}
$$

where $\lambda_{1}$ and $\lambda_{2}$ are the eigenvalues of $M$. It is well known that the maximum Lyapunov exponent, $\sigma_{\max }=\max \left\{\sigma_{1}, \sigma_{2}\right\}$, is used to characterize the chaotic behavior of the system. If $\sigma_{\max }>0$, the system behaves chaotically; otherwise, it is stable.

The chaotic behavior of the Ikeda map given by Eq. (1) changes with respect to the chaoticity parameter $B$. Fig. 2 and Fig. 3 show the variation of the maximum Lyapunov exponents and the bifurcation diagram of the Ikeda map for the parameter $B$ in the range of $(0,1]$, respectively.

As can be seen from Fig. 2 and Fig. 3, for $B>0.4$, the maximum Lyapunov exponent is positive and period

\section{Figure 2}

The variation of maximum Lyapunov exponent with respect to the chaoticity parameter

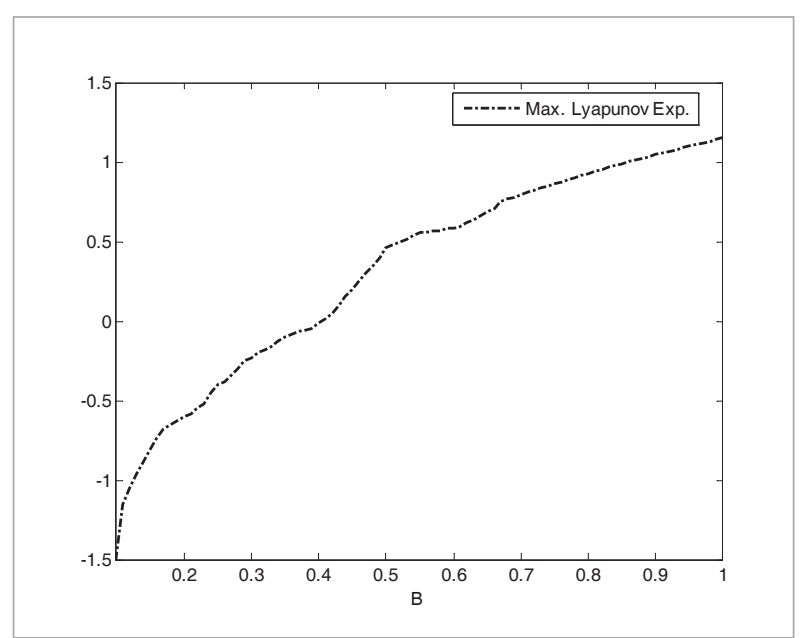


Figure 3

Bifurcation diagram

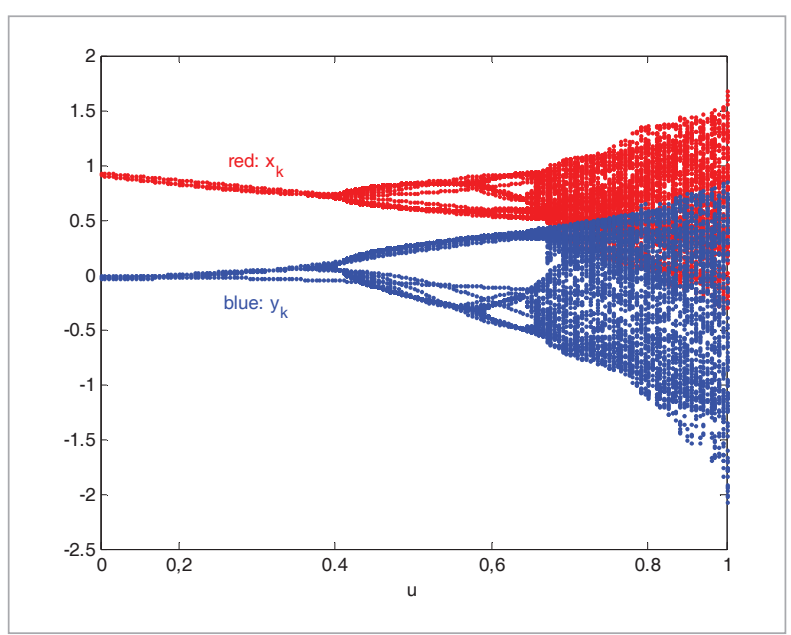

doubling occurs, which leads to chaotic behavior. In order to understand the stability of the fixed points, the magnitude of the eigenvalues of the Jacobian matrix given by Eq. (2) has been investigated. Fig. 4 shows the variation of the maximum eigenvalues, which correspond to the fixed points, with respect to the chaoticity parameter $B$.

\section{Figure 4}

The dependence of the fixed points on the chaoticity parameter

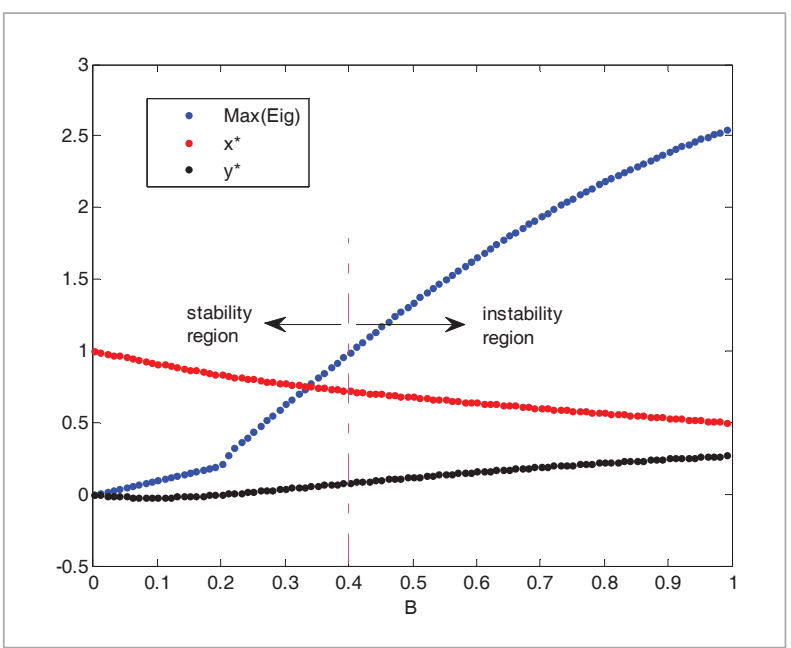

It is clear that, for $B>0.4$, the magnitude of the maximum eigenvalues is bigger than one. Therefore, the pairs of fixed points, $\left(x^{*}, y^{*}\right)$, corresponding to the $B$ values greater than " 0.4 " fall into the instability region, which means that all fixed points for $B>0.4$ are unstable. On the other hand, for $0<B<0.4$, all fixed points fall into the stability region.

From Fig. 4, it is seen that $x^{*}$ is monotonically decreasing in the interval $(0.5,0.91)$ and $y^{*}$ is monotonically increasing in the interval $(-0.02,0.27)$ with respect to $B$. Thus, in order to determine the target stable fixed point according to the chaoticity parameter $B$ in the stability region, the following linear interpolations can be utilized as:

$$
\begin{aligned}
& x^{*}=\operatorname{interp}\left(\overline{\mathrm{B}}, \overline{\mathrm{x}}, \mathrm{B}_{\mathrm{s}}\right), \\
& y^{*}=\operatorname{interp}\left(\overline{\mathrm{B}}, \bar{y}, \mathrm{~B}_{\mathrm{s}}\right),
\end{aligned}
$$

where interp is interpolation function, $\bar{x}, \bar{y}$ are the fixed point vectors and $\bar{B}$ is the chaoticity parameter vector in the range of $(0,1) . \mathrm{B}_{\mathrm{s}}$ can be chosen freely in the stability region, i.e. $(0,0.4)$. Considering together with Fig. 2, the maximum Lyapunov exponent of any fixed point in the stability region, as shown in Fig. 4, is negative. So, in this study, the aim is to keep the chaotic trajectory of the Ikeda system in the vicinity of the target stable fixed point that can be determined by Eq. (5).

\section{Alternative control scheme}

Although there have been many studies in the literature on the stabilization of the chaotic systems, it is still a difficult task to determine a suitable fixed point where all the Lyapunov exponents are negative. Among these studies, a time-delayed feedback controller developed in [26] is the most effective one. In it, the chaotic system is perturbed by small changes in control parameters in such a way that the largest Lyapunov exponent related to an unstable periodic orbit (UPO) becomes negative as shown in Fig. 5, so the UPO becomes stable and the chaotic trajectory converges to this stable fixed point.

As can be seen from Fig. 5, the largest Lyapunov exponent evaluated for different values of the control parameters, $R$ and $K$, is negative. Thus, stabilization can be achieved for all values of $R$. Although this 
method is very useful and simple for transforming the unstable fixed points to stable ones, it is not always possible to find an appropriate control parameter or the system can go unstable if the perturbation time is long.

\section{Figure 5}

The largest Lyapunov exponent for different control parameters

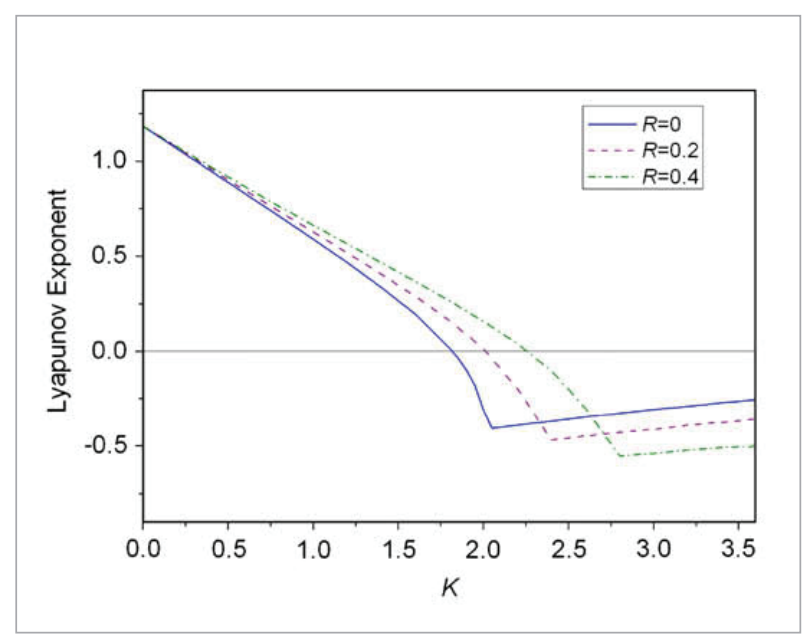

In this paper, in order to eliminate these drawbacks of the existing control methods, the eigenvalues of the Jacobian matrix of the chaotic system have been evaluated for different values of the chaoticity parameter, which leads to chaotic behaviour. The fixed points are stable for the chaoticity parameter that makes the maximum eigenvalue of the system smaller than "1". Based on the value of the maximum eigenvalues, a set of suitable fixed points has been created and the suitable one is determined by using a lookup table. Then, an adaptive neural network control scheme has been applied to chaotic system to force the chaotic trajectory to converge to the stable fixed point. Hence, the proposed method is not sensitive to variation in chaotic dynamics.

\section{Proposed control scheme}

The proposed control scheme is a back propagation neural network with a novel adaptive learning rate consisting of three layers of neurons (input layer, hidden layer and output layer), as shown in Fig. 6 [18].

\section{Figure 6}

The proposed neural network topological structure

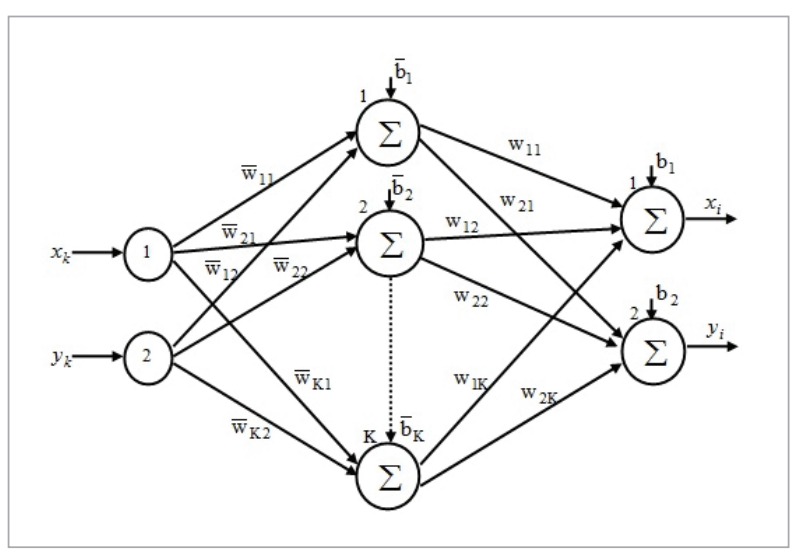

Here, $\left(x_{k}, y_{k}\right), k=1,2, \ldots . . N$, are the input patterns generated iteratively from Eq. (1); $N$ is the finite number of input patterns; $\left(x_{i}, y_{i}\right)$ are the output patterns that should have to be approximated to the fixed points, $\left(x^{*}, y^{*}\right)$. The generalized model of the proposed control system is shown in Fig. $\%$.

\section{Figure 7}

The model of the proposed control scheme

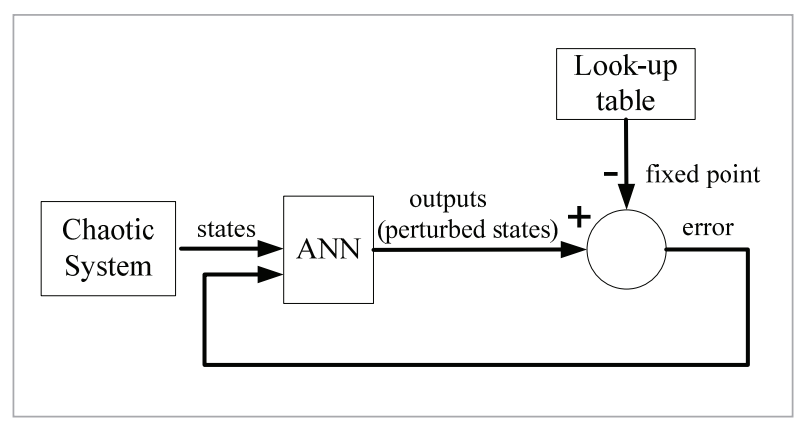

In the adaptive neural network (ANN) block in Fig. 7 , the error is back-propagated to update the weights, and the outputs (perturbed states) are converged to the stable fixed point. The learning phase of the ANN has two steps. In the first step, the output of the network is calculated based on the structure of the network using previous weights and bias values from the first layer to the forward. The following calculations are done in the first step.

The input to the $k$ th neuron of the hidden layer is denoted by $\mathrm{I}_{\mathrm{K}}$ and is given by: 


$$
I_{K}=x_{k} \bar{w}_{K 1}+y_{k} \bar{w}_{K 2}+\bar{b}_{K}
$$

where

$\bar{w}_{K 1}$ and $\bar{w}_{K 2}$ are the weights between the $k$ th neuron of the hidden layer. $\bar{b}_{K}$ is the bias value of the $k$ th neuron in the hidden layer. By applying the tangent sigmoid activation function $F$ on $\mathrm{I}_{\mathrm{K}}$, the output $\bar{O}_{p K}$ is obtained as:

$$
\begin{aligned}
& F(x)=\frac{e^{x}-e^{-x}}{e^{x}+e^{-x}} \\
& \bar{O}_{p K}=F\left(I_{K}\right) .
\end{aligned}
$$

The network outputs are given by:

$$
\begin{aligned}
& x_{i}=F\left(\sum_{k=1}^{K} \bar{O}_{p K} w_{1 K}+b_{1}\right), \\
& y_{i}=F\left(\sum_{k=1}^{K} \bar{O}_{p K} w_{2 K}+b_{2}\right) .
\end{aligned}
$$

In the second step, the weights and bias values are updated adaptively based on the error values, $E_{x_{i}}=x^{*}-x_{i}, E_{y_{i}}=y^{*}-y_{i}$, from the last layer to the back. The adaptation rules for the weight and bias values between the output and hidden layers are calculated by the following equations:

$$
\begin{aligned}
& w_{1 \text { Knew }}=w_{1 \text { Kold }}+\Delta w_{1 K}(k+1), k=1,2 \ldots N, \\
& w_{2 \text { Knew }}=w_{2 \text { Kold }}+\Delta w_{2 K}(k+1), k=1,2 \ldots N . \\
& b_{1 \text { new }}=b_{1 \text { old }}+\Delta b_{1}(k+1), \\
& b_{2 \text { new }}=b_{2 \text { old }}+\Delta b_{2}(k+1) .
\end{aligned}
$$

In Eqs. (11), (12), second terms are calculated as:

$$
\begin{aligned}
& \Delta w_{1 K}(k+1)=\eta_{x} \delta_{1 K} \bar{O}_{p K} \\
& \Delta w_{2 K}(k+1)=\eta_{v} \delta_{2 K} \bar{O}_{p K} \\
& \Delta b_{1}(k+1)=\eta_{x} \delta_{1 K} \\
& \Delta b_{2}(k+1)=\eta_{y} \delta_{2 K} \\
& \delta_{1 K}=E_{x_{i}} x_{i}\left(1-x_{i}\right) \\
& \delta_{2 K}=E_{y_{i}} y_{i}\left(1-y_{i}\right)
\end{aligned}
$$

where $\eta_{x}$ and $\eta_{y}$ are the adaptive learning rates which are varied according to the error functions and updated as:

$$
\eta_{x, y}=\left\{\begin{array}{l}
\eta_{x, y} \phi, \phi>1,\left|\mathrm{E}_{\mathrm{x}_{\mathrm{i}+1}, y_{i+1}}\right| \leq\left|\mathrm{E}_{\mathrm{x}_{\mathrm{i}}, y_{i}}\right| \\
\eta_{\mathrm{x}, \mathrm{y}} \varsigma, \varsigma<1,\left|\mathrm{E}_{\mathrm{x}_{\mathrm{i}+1}, y_{i+1}}\right|>\left|\mathrm{E}_{\mathrm{x}_{\mathrm{i}}, y_{i}}\right| \\
\eta_{\mathrm{x}, \mathrm{y}},\left|\mathrm{E}_{\mathrm{x}_{\mathrm{i}}, \mathrm{y}_{\mathrm{i}}}\right| \leq \mathrm{E}_{\mathrm{t}}, \forall \mathrm{i} \in \mathrm{N}
\end{array} .\right.
$$

This rule is applied until a desired error response, $E_{t}$, is achieved. In a similar way, the adaptation rules for the weight and bias values between the hidden and input layers are calculated by the following equations:

$$
\begin{aligned}
& \bar{w}_{K 1 \text { new }}=\bar{w}_{K 1 \text { old }}+\Delta \bar{w}_{K 1}(k+1), k=1,2 \ldots N, \\
& \bar{w}_{K 2 \text { new }}=\bar{w}_{K 2 \text { old }}+\Delta \bar{w}_{K 2}(k+1), k=1,2 \ldots N, \\
& \bar{b}_{\text {Knew }}=\bar{b}_{\text {Kold }}+\Delta \bar{b}_{K}(k+1), k=1,2 \ldots . N .
\end{aligned}
$$

In Eqs. (17), (18), second terms are calculated as:

$$
\begin{aligned}
& \Delta \bar{w}_{K 1}(k+1)=\eta_{z} \bar{\delta}_{K 1} x_{i}, \\
& \Delta \bar{w}_{K 2}(k+1)=\eta_{z} \delta_{K 1} y_{i}, \\
& \Delta \bar{b}_{K}(k+1)=\eta_{z} \bar{\delta}_{K 1}, \\
& \bar{\delta}_{K 1}=\left(\delta_{1 K} w_{1 \text { Kold }}+\delta_{2 K} w_{2 \text { Kold }}\right) \mathrm{c}(\mathrm{k}), \\
& c(k)=\bar{O}_{p K}\left(1-\bar{O}_{p K}\right),
\end{aligned}
$$

where $\eta_{z}$ is also changed adaptively as:

$$
\eta_{z}=\left\{\begin{array}{l}
\eta_{z} \phi,\left|\mathrm{E}_{\mathrm{x}_{\mathrm{i}+1}}\right|+\left|\mathrm{E}_{\mathrm{y}_{\mathrm{i}+1}}\right| \leq\left|\mathrm{E}_{\mathrm{x}_{\mathrm{i}}}\right|+\left|\mathrm{E}_{\mathrm{y}_{\mathrm{i}}}\right| \\
\eta_{\mathrm{z}} \varsigma,\left|\mathrm{E}_{\mathrm{x}_{\mathrm{i}+1}}\right|+\left|\mathrm{E}_{\mathrm{y}_{\mathrm{i}+1}}\right|>\left|\mathrm{E}_{\mathrm{x}_{\mathrm{i}}}\right|+\left|\mathrm{E}_{\mathrm{y}_{\mathrm{i}}}\right| . \\
\eta_{\mathrm{z}},\left|\mathrm{E}_{\mathrm{x}_{\mathrm{i}}}\right|+\left|\mathrm{E}_{y_{i}}\right| \leq \mathrm{E}_{\mathrm{t}} \text { for } \forall \mathrm{i} \in \mathrm{N}
\end{array}\right.
$$

where $\phi>1$ and $\varsigma<1$ are appropriate constants. With above updating rules, the output of the network converges to the target stable fixed point.

\section{Simulation results and discussion}

In this section, numerical simulations are carried out on Ikeda system to show the effectiveness of the proposed 
control method. The objective is to stabilize the chaotic trajectory of Ikeda map given by Eq. (1) to a stable target fixed point, which has been determined by Eq. (5).

In this study, $\mathrm{B}_{\mathrm{s}}$ was chosen as 0.3 in the interval of $(0,0.4)$, where the maximum Lyapunov exponent is negative. For $\mathrm{B}_{\mathrm{s}_{*}}=0.3$, the stable fixed point has been calculated as $x^{*}=0.772, y^{*}=0.038$. For this target point, the proposed neural network has been trained using a set of some arbitrary trajectories with random initial values, and a training set with 500 input patterns has been constructed for test purpose.

The ANN training parameters are given in Table 1. The optimal values of these parameters are obtained based on the simulation trials.

\section{Table 1}

ANN training parameters

\begin{tabular}{c|c}
\hline Parameters & Values \\
\hline $\begin{array}{c}\text { Transfer function in hidden and } \\
\text { output layers }\end{array}$ & tansig \\
\hline Number of hidden neurons & 10 \\
\hline Initial weights and bias & {$[0,0]$} \\
\hline Learning rates, $\eta_{x}=\eta_{y}=\eta_{z}$ & 0.1 \\
\hline$\phi$ & 2 \\
\hline$\varsigma$ & 0.9 \\
\hline
\end{tabular}

Fig. 8 shows the time series plot of the system states, when the proposed control scheme is applied.

\section{Figure 8}

Time series plot



As can be seen from Fig. 8, the state variables reach the stable target fixed point immediately after the control action has been switched on at $k=500$.

\section{Figure 9}

Variation of maximum Lyapunov exponent of the controlled system (after $k=500$ )

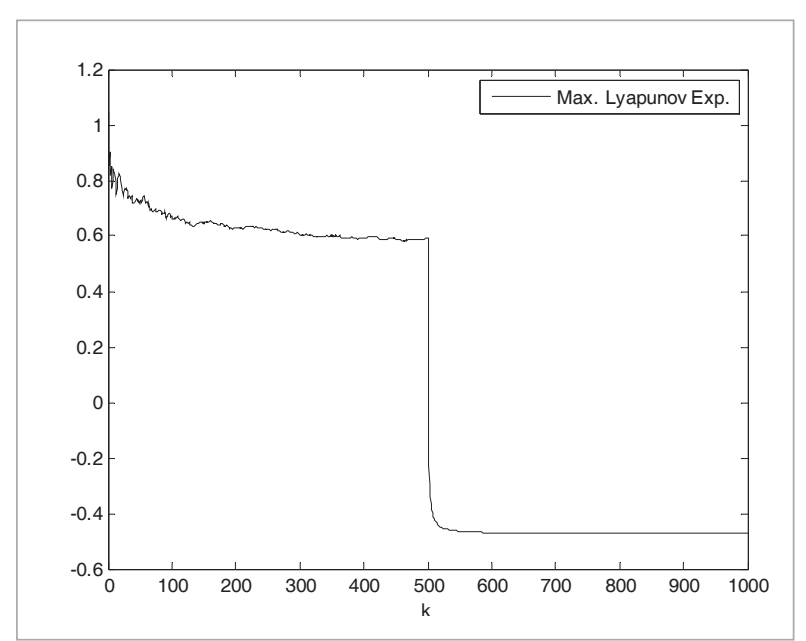

Fig. 9 shows the variation of the maximum Lyapunov exponent, $\sigma_{\max }$, of the chaotic system as well as the controlled system for this training set. It is clear that the positive Lyapunov exponent of the chaotic system becomes negative after control action has been taken.

\section{Conclusions}

In this paper, the control of chaos, which may occur in electronic systems, has been studied. For this purpose, a neural network control scheme with an adaptive learning rate has been proposed to control the chaotic trajectory of the Ikeda type chaotic system in the vicinity of the stable fixed point. The stability of the fixed points has been examined by calculating the eigenvalues of the Jacobian matrix at different values of the chaoticity parameter in a certain range that affects the chaotic properties of the system. The variation of the maximum Lyapunov exponent with respect to the chaoticity parameter has been investigated, and a relationship between the maximum Lyapunov exponent and the stability of the fixed points has been presented. Simulation studies showed that the proposed method can successfully stabilize the chaotic trajectory of the system to the target stable fixed point, where the maximum Lyapunov exponent is negative. 


\section{References}

1. Cai, G., Zhou, W., Tan, Z. Stabilization of higher periodic orbits of discrete-time chaotic systems. International Journal of Nonlinear Science, 2007, 4(2), 118-126.

2. Chang, Y. C. A robust tracking control for a class of uncertain chaotic systems. Asian Journal of Control, 2013, 15(6), 1752-1763. https://doi.org/10.1002/asjc.740

3. Crofts, J. J., Davidchack, R. L. On the use of stabilization transformations for detecting unstable periodic orbits in high-dimensional flows. Chaos, 2009, 19, 793-803. https://doi.org/10.1063/1.3222860

4. Durdu, A., Özcerit, A. T., Uyaroğlu, Y. A novel chaotic system for secure communication applications. Information Technology and Control, 2015, 44(3), 271-278. https://doi.org/10.5755/j01.itc.44.3.7720

5. Dutta, T. K., Jain, A. K. Controlling of chaos in some nonlinear maps. International Journal of Statistika and Mathematika, 2003, 7, 67-7\%.

6. Fu, S. H., Lu, Q. S. Set stability of controlled Chua's circuit under a non-smooth controller with the absolute value. International Journal of Control, Automation and Systems, 2014, 12, 507-51\%. http://link.springer. com/article/10.1007/s12555-013-0372-6

7. Fuh, C. C., Tsai, H. H., Tung, P. C. Stabilizing unstable periodic orbits via universal input-output delayed-feedback control. Nonlinear Dynamics, 2005, 40, 107-117. https://doi.org/10.1007//s11071-005-4575-0

8. Gökce, K., Uyaroğlu, Y. Controlling the chaotic discrete-Henon system using a feedforward neural network with an adaptive learning rate. Turkish Journal of Electrical Engineering and Computer Science, 2013, 21, 793-803. https://doi.org/10.3906/elk-1109-58

9. Haken, H. Chaos and Order in Nature. Springer, Berlin-Heidelberg, 1981. https://doi.org/10.1007/978-3642-68304-6

10. Hernandez, C., Martinez, A., Castellanos, J., Mingo, F. L. Controlling chaotic nonlinear dynamical systems. The 6th IEEE International Conf. on Electronics, Circuits and Systems, 1999, 1231-1234. https://doi.org/10.1109/ icecs.1999.814391

11. Hirasawa, K., Murata, J., Hu, J., Jin, C. Chaos control on universal learning networks. IEEE Transactions on Systems, Man and Cybernetics, Part C (Applications and Reviews), 2000, 30(1), 95-104. https://doi. org/10.1109/5326.827458

12. Hong, Z., Jie, Y., Jiao, W., Wang, Y. General method of controlling chaos. Physical Review, Part E., 1996, 53, 299-306. https://doi.org/10.1103/PhysRevE.53.299
13. Huang, J., Li, C., He, X. Stabilization of a memristor-based chaotic system by intermittent control and fuzzy processing. International Journal of Control, Automation and Systems, 2013, 11, 643-647. https://link. springer.com/article/10.1007/s12555-012-9323-x

14. Ikeda, K. Multiple-valued stationary state and its instability of the transmitted light by a ring cavity system. Optics Communications, 1979, 30(2), 257-261. https:// doi.org/10.1016/0030-4018('79)90090-77

15. Kocamaz, U. E., Uyaroğlu, Y., Kizmaz, H. Control of Rabinovich chaotic system using sliding mode control. International Journal of Adaptive Control and Signal Processing, 2014, 28, 1413-1421. https://doi.org/10.1002/ acs.2450

16. Kocamaz, U. E., Göksu, A., Taskın, H., Uyaroğlu, Y., Kizmaz, H. Synchronization of chaos in nonlinear finance system by means of sliding mode and passive control methods: A comparative study. Information Technology and Control, 2015, 44(2), 172-181. https:// doi.org/10.5755/j01.itc.44.2.7732

17. Kwon, O. J., Park, J. D., Lee, H. Stabilizing chaos to fixed points by continuous proportional feedback. Journal of the Korean Physical Society, 2001, 38, 635-641.

18. Lalithakumari, S., Sheelarani, B., Venkatraman, B. Artificial neural network based classification of austenitic stainless steel weld defects in tofd technique. Indian Journal of Computer Science and Engineering, 2012, 2(6), 845-849.

19. Li, D. M., Wang, Z. O. Control of unknown chaotic systems based on neural predictive control. Communications in Theorical Physics, 2003, 40(4), 439-442. https://doi.org/10.1088/0253-6102/40/4/439

20. Lian, K. Y., Liou, J. J. Low effort control for chaotic systems via a fuzzy model based approach. Proceedings of the 16th IFAC World Congress, 2005, 1119. https://doi. org/10.3182/20050703-6-cz-1902.01120

21. Lu, J., Wei, R., Wang, X., Wang, Z. Backstepping control of discrete-time chaotic systems with application to the Henon system. IEEE Transactions on Circuits and Systems I: Fundamental Theory and Applications, 2001, 48(11), 1359-1363. https://doi.org/10.1109/81.964429

22. Luo, R. The robust adaptive control of chaotic systems with unknown parameters and external disturbance via a scalar input. International Journal of Adaptive Control and Signal Processing, 2015, 29(10), 1296-130\%. https://doi.org/10.1002/acs.2540

23. Mascolo, S., Grassi, G. Controlling chaotic dynamics using backstepping design with application to the Lorenz 
system and Chua's circuit. International Journal of Bifurcation and Chaos, 1999, 9(7), 1425-1434. https://doi. org/10.1142/S0218127499000973

24. Onma, O. S., Olusola, O. I., Njah, A. N. Control and synchronization of chaotic and hyperchaotic Lorenz systems via extended backstepping techniques. Journal of Nonlinear Dynamics, 2014, 2014, Article ID 861727.

25. Ott, E., Grebogi, C., Yorke, J. A. Controlling chaos. Physical Review Letters, 1990, 64, 1196-1199. https://doi. org/10.1103/PhysRevLett.64.1196

26. Paula, A. S., Savi, M. A. Controlling chaos in a nonlinear pendulum using an extended time-delayed feedback control method. Chaos, Solitons and Fractals, 2009, 42(5), 2981-2988. https://doi.org/10.1016/j.chaos.2009.04.039

27. Salamon, M., Tomaz, D. Danger of chaos in a second order digital filter. Informacije MIDEM, 2000, 30, 37-42.

28. Skufca, J. D., Bollt, E. M. Feedback control with finite accuracy: More knowledge and better control for free.
Physica D: Nonlinear Phenomena, 2003, 179(1), 18-32. https://doi.org/10.1016/S0167-2789(03)00012-5

29. Uyaroğlu, Y., Varan, M., Emiroğlu, S. Chaotic ferroresonance and its control with sliding mode technique for voltage transformer circuits: A case study of manual single phase switching operation in three-phase transmissiom system. Optoelectronics and Advanced Materials - Rapid Communications, 2012, 6, 498-503.

30. Yu, S. H., Kang, H. S., Kim, Y. T., Hyun, C. H., Park, M. Fuzzy adaptive modular design of uncertain chaotic Duffing oscillators. International Journal of Control, Automation and Systems, 2014, 12(1), 188-194. https://doi. org/10.1007/s12555-012-0448-8

31. Zhang, Q., Shu, Y., Zhang, W. Controlling and synchronization of a new Lorenz-like chaotic system. J. of East China Normal University, 2010, 2010(1), 52-61.

32. Zong, X. P., Geng, Y. Control chaotic systems based on BP neural network with a new perturbation. International Conference on Wavelet Analysis and Pattern Recognition, 2009, 166-170.

\section{Summary / Santrauka}

A neural network control scheme with a novel adaptive learning rate is proposed to stabilize the chaotic trajectory of the chaotic system to a stable fixed point. A new approach is proposed to determine the stability of the fixed points in which the eigenvalues of the Jacobian matrix of the chaotic system at different values of the chaoticity parameter are evaluated and a look-up table is created to find a suitable fixed point that has a negative Lyapunov exponent. During learning phase of the neural network, weight parameters are adjusted so that the chaotic trajectory converges to a stable fixed point and the maximum Lyapunov exponent of the controlled system becomes negative. The effectiveness of the proposed method is investigated through simulation studies on 2 dimensional Ikeda map, which is produced by a semiconductor laser system.

Straipsnyje siūloma neuroninio tinklo valdymo schema, pasižyminti nauju adaptyviu mokymosi greičiu tam, kad būtų galima stabilizuoti chaotiškos sistemos chaotišką trajektoriją iki stabilaus ir pastovaus taško. Siūlomas naujas metodas, leidžiantis nustatyti pastovių taškų, kuriuose vertinamas chaotiškos sistemos Jakobiano matricos tikrinių verčių stabilumas skirtinguose chaotiškumo parametrų įverčiuose. Sudaryta lentelè, kurioje galima rasti tinkamą pastovų tašką, turintị neigiamą Liapunovo rodiklį. Neuroninio tinklo mokymosi fazès metu svorio parametrai sureguliuojami taip, kad chaotiška trajektorija konverguoja i̇ stabilu pastovų tašką, maksimalus valdomos sistemos Liapunovo rodiklis tampa neigiamas. Siūlomo metodo efektyvumas tiriamas per simuliacinius 2D Ikedos žemėlapio, sukurto puslaidininkio lazerio sistema, tyrimus. 